\title{
A educação cooperativa como gerador de mudanças sociais: um estudo sobre a 6o Semana da educação financeira na cidade de Itamaraju/BA
}

\author{
The cooperative as a generator of social changes: a study about the $6^{\text {th }}$ Week of \\ financial education in the city of Itamaraju/BA
}

\begin{abstract}
Resumo
O presente artigo discorre sobre os princípios cooperativos constituintes dos sistemas de cooperação, enfatizando os princípios da educação, formação e Informação, e do Interesse pela comunidade. Nesse sentido o problema apontado é como a educação cooperativista pode contribuir na formação e mudança de pensamento das crianças no desenvolvimento da educação financeira? Sendo assim os objetivos apresentados são: analisar a educação cooperativa e suas contribuições na mudança de pensamento das crianças enfatizando sobre a educação financeira, e os objetivos específicos são contextualizar o cooperativismo no Brasil e no mundo; compreender o processo da educação financeira no âmbito escolar e exemplificar a 6. a semana da educação financeira proposta pelo Banco Central e executada pelo instituo SICOOB como modelo motivador para o despertar financeiro. A metodologia desenvolvida na pesquisa tem uma abordagem qualitativa, sendo representada pela pesquisa bibliográfica e pesquisa de campo, descrevendo uma breve visão histórica sobre o cooperativismo, a educação e a sociedade.
\end{abstract}

Palavras-chave: Cooperação, educação, mudança, desenvolvimento, formação.

\begin{abstract}
The present article discourses about the Cooperative Principles constituents to the systems of cooperation, emphasizing the Principles of Education, Formation and Information and the Public Interests. In this sense the pointed out problem is how the cooperative education may contribute to children's formation and change in the way of thinking about the development of financial education? Thus the presented goals are: analyze the cooperative education and its contributions in the change of thinking of children focusing on the financial education and the specific goals are contextualize the Cooperativism in Brasil and around world; understand the process of financial education in the school scope and exemplify the Financial Education Week proposed by the Central Bank and performed by the Sicoob Institute. The methodology developed in the research has a qualitative approach. Being represented by bibliographic research and field research, describing a short historical sight about cooperativism, education and society.
\end{abstract}

Keywords: Cooperation, education, change, development, formation.

Daniele Carmo Scopel ${ }^{\mathrm{I}}$, Estella Oliveira dos Santos ${ }^{\mathrm{II}}$

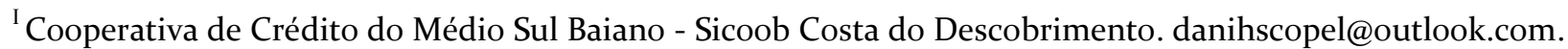

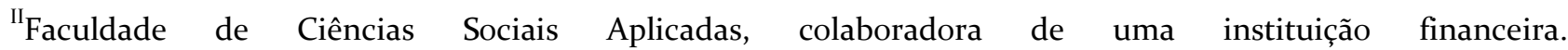
oliveira.estella@hotmail.com 


\section{Introdução}

A realidade vivida por muitas crianças e jovens no país tem se tornado algo preocupante. A medida que as condições sociais e financeiras não são favoráveis para o seu desenvolvimento. Oportunidades de risco são lhes apresentadas como única opção a ser seguida, causando assim alarde aos "ouvidos" públicos e sociais.

A problemática apontada passa por um grande crescimento de pessoas endividadas no Brasil, percebe-se que ainda existe uma falta de educação financeira da família que não é repassada para as crianças e adolescentes, sendo assim fica evidente a ausência de maturidade financeira, pois falta orientação dos pais, dos órgãos governamentais e principalmente das escolas que é o seu principal referencial no processo de formação na sociedade capitalista. Nesta perspectiva surge o problema estrutural dessa pesquisa que é como a educação cooperativista pode contribuir na formação e mudança de pensamento das crianças no desenvolvimento da educação financeira?

Neste contexto apresenta-se o objetivo geral, da pesquisa que é analisar a educação cooperativa e suas contribuições na mudança de pensamento das crianças enfatizando sobre a educação financeira. Visando desenvolver uma melhor estrutura da pesquisa foram elaborados três objetivos específicos que têm o intuito de: contextualizar o cooperativismo no Brasil e no mundo; compreender o processo da educação financeira no âmbito escolar e exemplificar a 6. a semana da educação financeira proposta pelo Banco Central e executada pelo instituo SICOOB ( Instituto SICOOB foi criado em 2004 com o objetivo de difundir a cultura cooperativista e contribuir para a promoção do desenvolvimento sustentável das comunidades) como modelo motivador para o despertar financeiro.

A pesquisa apresenta inicialmente uma justificativa para o estudo da temática educação financeira, ficando evidente que não existe uma preocupação do governo em capacitar a população para uma melhor educação financeira, neste sentido este estudo se mostra necessário e relevante trazendo informações que darão subsídios para um melhor direcionamento dos gastos financeiros, apontando nesse processo um olhar para as futuras gerações que irão ser os futuros consumidores da sociedade capitalista.

Sendo assim, a proposta dessa pesquisa vem no sentido de levar mais conhecimento para essa geração mirim que ainda não tem uma noção clara dos seus gastos e investimentos financeiros.

Novas formas de mudanças do cenário social atual são estudadas e propostas a todo o momento. Alguns conceitos futuristas são agregados a ideias contemporâneas, mas sem muita previsão de sucesso, no entanto, conceitos antigos e que comprovadamente são instrumentos de boa gestão de processos sociais e negociais são esquecidos.

A ideia de cooperação apresentada pelo conceito cooperativista prevê a interação entre pessoas que possuem um mesmo objetivo comum que atuam em prol do alcance de benefícios mútuos, onde cada integrante é responsável igualmente pelos interesses e ações executados. A premissa básica do cooperativismo parte da ideia de cooperar com o próximo, trabalhando em conjunto e de forma interligada para a maximização dos impactos positivos.

A contribuição dos ensinamentos cooperativistas no âmbito escolar prevê a inserção de ideias de trabalho em equipa, controle e conhecimento financeiro, formas de atuação e comportamento mediante diversas situações, além de introduzir de forma objetiva a preocupação com a comunidade.

\section{Referencial Teórico}

\section{1 Breve Histórico do Cooperativismo}

O cooperativismo surgiu numa cidade do Noroeste da Inglaterra por meados do século XIX, através de consequências do liberalismo econômico. Este surgimento buscava formas alternativas para melhorar a vida da classe trabalhadora. Tornando-se o meio mais prático pelo qual coletivamente essa classe tentava sobreviver, tendo ainda um grande diferencial, pois são organizações de pessoas e em que pese exercer um papel nas movimentações do mercado, elas não 
visam apenas o lucro e sim o desenvolvimento econômico e social dos cooperados. A base deste surgimento se deu a partir de dois problemas enfrentados na época, o consumidor e o consumo.

Desde do século XVII já haviam alguns autores que se interessavam em estudar o problema relacionado ao consumo, no entanto, foi apenas no século XIX, que este assunto se tornou sério para os economistas da época. Muitos consumidores começaram a ter consciência do seu poder de compra, sendo assim, muitos desses consumidores começaram a se unir em sociedades Cooperativas com o objetivo de se opor aos excessos dos produtores e dos intermediários, assim surgiu o cooperativismo, representando uma ponte entre os desequilíbrios do liberalismo econômico.

O surgimento do Cooperativismo liga-se ao desenvolvimento do capitalismo industrial na Europa do século XVIII, como expressão de um movimento operário, reagindo ás condições de extrema exploração então existentes. Neste contexto, as crianças de menos de nove anos trabalhavam das seis da manhã ás seis da noite e os adultos tinha uma jornada de catorze horas de trabalho. (RIOS, G. 2007, p.23)

Nessa perspectiva existem outros autores que apresentam definições referente ao cooperativismo a seguir:

Cooperativismo no sentido de doutrina que tem por objeto a correção do social pelo econômico através de associações de fim predominantemente econômico, ou seja, as cooperativas; cooperativas no sentido de sociedades de pessoas organizadas em bases democráticas, que visam não só a suprir seus membros de bens e serviços como também a realizar determinados programas educativos e sociais. Trata-se, insistimos, de sociedade de pessoas e não de capital, sem interesse lucrativo e com fins econômico-sociais. Seu funcionamento se inspira nos chamados "Princípios dos Pioneiros de Rochdale": adesão livre, gestão democrática, juros módicos ao capital, retorno proporcional às operações, transações a dinheiro, neutralidade política, religiosa e ética e desenvolvimento do ensino. (PINHO, 2004, p.8).

Com base nos autores apresentados é sabido que o cooperativismo realizado por pessoas apropriadas e com conhecimento é capaz de transformar o mundo, portanto, surge-se então a necessidade de aplicação da educação financeira. Segundo Pinho (2004) afirmou que "as cooperativas ganham destaque no mercado como elemento de progresso das economias subdesenvolvidas" esta que não consiste somente em aprender a economizar, cortar gastos, poupar e acumular dinheiro, mas buscar uma melhor qualidade de vida tanto hoje quanto no futuro, proporcionando a segurança material necessária para obter uma garantia para eventuais imprevistos, dessa forma é preciso que a educação financeira alcance o máximo da comunidade ao qual as Cooperativas estão inseridas.

\subsection{A primeira cooperativa considerada como um marco histórico mundial.}

Em 1843 em Rochdale cidade da Inglaterra, 28 tecelões pobres, se reuniram em assembleia, tendo o objetivo de encontrar soluções para a situação econômica o qual estavam vivendo.

Surgiram-se então, algumas propostas, dentre elas, a aprovada foi a fundação de um armazém cooperativo, eles economizaram durante um ano para a construção do armazém e em dezembro de 1844, houve a grande inauguração, neste armazém continha alguns gêneros alimentícios. Sendo assim uma forma que eles encontraram para propiciar uma melhora na qualidade de vida, em que estavam enfrentando, e tornando-se um marco histórico nas relações entre empregado e empregador.

"Os pioneiros de Rochdale conseguiram provar na prática que era possível criar uma alternativa de trabalho e renda, sem grande capital e dentro do capitalismo; tudo através da associação de pessoas" (ABRANTES, 2004, p. 44-45).

Foi aprovado pelos cooperados de Rochdale o estatuto da cooperativa e um plano de trabalho, que incluiu ações educacionais para os associados. 
149 | A educação cooperativa como gerador de mudanças sociais: um estudo...

\subsection{O cooperativismo no Brasil}

No Brasil, a primeira cooperativa foi fundada em outubro de 1889, na cidade de Ouro Preto no estado de Minas Gerais, a sua área de atuação era de consumo com o nome de Sociedade Cooperativa Econômica dos Funcionários públicos de Ouro Preto, que ao passar do tempo se expandiu para Pernambuco, Rio de Janeiro, Rio Grande do Sul e São Paulo, posteriormente no ano de 1902, fundou a segunda cooperativa, atuando no ramo de crédito na cidade de Nova Petropólis no sul do país a SICREDI Pioneira, inspirada pelo patrono do cooperativismo do Brasil o padre Theodor Amstad, atualmente está cooperativa é uma das maiores do país, no entanto, a história do cooperativismo brasileiro iniciou-se com experiências através das pré-cooperativas, conforme afirma Pinho:

Considera-se como experiências pré-cooperativas todas aquelas que, pautadas no princípio da cooperação, possibilitaram a união de pessoas em volta de interesse aglutinadores. Desse modo, por inspiração de intelectuais ou na forma espontânea e comunitária de ajuda mútua, temos alguns exemplos de destaque sobre experiências anteriores à constituição da primeira cooperativa da história, a saber. (PINHO, 1999, p.56).

Tabela 1.

É possível realizar o acompanhamento do histórico das pré-cooperativas no Brasil, conforme 
Tabela 1 - Histórico das pré-cooperativas no Brasil

\begin{tabular}{|c|c|c|c|}
\hline $\mathbf{N}$ & Período & Experiência Pré-Cooperativa & Detalhes \\
\hline $\mathbf{1}$ & $1530-1540$ & $\begin{array}{c}\text { Movimentos messiânicos } \\
\text { sebastianistas, de origem } \\
\text { portuguesa }\end{array}$ & $\begin{array}{l}\text { Encabeçamentos por Barrara } \\
\text { (Gonçalo Annes Bandarra - } \\
\text { Sapateiro e profeta português), } \\
\text { com algum conteúdo de } \\
\begin{array}{l}\text { cooperativismo comunitário } \\
\text { integral. }\end{array}\end{array}$ \\
\hline 2 & $1600-1695$ & República de Palmares & $\begin{array}{l}\text { Envolveu escravos de grandes } \\
\text { engenhos de açúcar de } \\
\text { Pernambuco e de outras regiões, } \\
\text { além de índios, mamelucos, } \\
\text { mulatos e brancos, computando } \\
\text { uma população estimada entre } 20 \\
\text { e } 30 \text { mil pessoas, em uma área de } \\
350 \text { quilômetros. Praticavam a } \\
\text { solidariedade e a democracia. A } \\
\text { terra era propriedade coletiva. }\end{array}$ \\
\hline 3 & $1610-1768$ & $\begin{array}{l}\text { Experiências associativas } \\
\text { isoladas }\end{array}$ & $\begin{array}{l}\text { República comunista Cristã dos } \\
\text { Guaranis - bacia dos Rios } \\
\text { Paraguai, Paraná e Uruguai, } \\
\text { extensa área das reduções jesuítas } \\
\text { dos povos Guaranis. }\end{array}$ \\
\hline 4 & 1817 & $\begin{array}{l}\text { Silvestre José dos Santos reúne } \\
\text { fiéis para instalação do paraíso } \\
\text { terrestre, quando D. Sebastião } \\
\text { regressaria da ilha de Brumas }\end{array}$ & $\begin{array}{l}\text { Movimento messiânico brasileiro } \\
\text { que defende uma sociedade com } \\
\text { algumas características de } \\
\text { cooperativas } \\
\text { integrais. }\end{array}$ \\
\hline 5 & 1850 em diante & $\begin{array}{c}\text { Atividades associativas de } \\
\text { amparo mútuo, assistência à } \\
\text { saúde, esportes, música, artes, } \\
\text { etc. }\end{array}$ & $\begin{array}{l}\text { Imigrantes germânicos } \\
\text { proprietários de pequenas glebas } \\
\text { desenvolvem centenas de } \\
\text { experiências. A mais abrangente é } \\
\text { a Bauerverein. }\end{array}$ \\
\hline 6 & $1874-1876$ & Canudos & $\begin{array}{l}\text { Antônio Conselheiro constrói } \\
\text { uma "cidade santa" em arraial do } \\
\text { município de Monte Santo } \\
\text { (nordeste da Bahia), à margem do } \\
\text { Rio Vasa Barris, com algumas } \\
\text { características de cooperativismo } \\
\text { comunitário integral. }\end{array}$ \\
\hline 7 & 1885 & $\begin{array}{c}\text { Atuação do Padre Theodor } \\
\text { Amstad }\end{array}$ & $\begin{array}{l}\text { Nesta época, torna-se importante } \\
\text { líder rural e cooperativista } \\
\text { juntamente com João Rick e Hugo } \\
\text { Metzler. Sua atuação vai se } \\
\text { destacar especialmente na criação } \\
\text { e no funcionamento de } \\
\text { Associação Riograndense de } \\
\text { Agricultores, até 1909. }\end{array}$ \\
\hline 8 & 1889 & $\begin{array}{l}\text { Surgimento de uniões, } \\
\text { associações, ligas e sindicatos }\end{array}$ & $\begin{array}{l}\text { Com a proclamação da República, } \\
\text { os trabalhadores livres criaram } \\
\text { instituições fundamentadas na } \\
\text { cooperação, como forma de } \\
\text { resistir a precarização do trabalho } \\
\text { e superar as dificuldades } \\
\text { econômicas. }\end{array}$ \\
\hline
\end{tabular}

Fonte: Revista Fundamentos do Cooperativismo (2017)

Evidencia-se que as experiências com pré-cooperativas aconteceram em diversos ano da história, e assim em seguida surgindo as cooperativas, estas que são:

A Aliança Cooperativista Internacional - ACI define cooperativa como - uma associação autônoma de pessoas que se unem, voluntariamente, para satisfazer 
aspirações e necessidades econômicas, sociais e culturais comuns, por meio de um empreendimento de propriedade coletiva e democraticamente geridoll. Este modelo cooperativo tem sido usado para viabilizar negócios em vários campos de atuação, de modo a propiciar melhor entendimento da formação, estrutura, composição e participação nos diversos setores econômicos. (Revista Sebrae, Cooperativa de Crédito, 2009, p. 8-9).

\subsection{A cooperação}

As ações de cooperar são notórias desde os primórdios da humanidade, a população não precisava de dinheiro, as pessoas moravam em cavernas, utilizavam pele de animal como coberta e os seus alimentos eram provenientes de resultados de caça e pesca. Quando o número de habitantes na terra começou a crescer criaram-se grupos chamados de comunidades, daí em diante iniciou-se o desenvolvimento da agricultura, da produção de ferramentas e de vasilhas para cozinhar.

No momento em que integrantes de uma comunidade necessitavam de determinados objetos que não possuíam e não desenvolviam, iam a uma outra comunidade mais próxima e realizavam trocas por outras coisas, ou seja, os membros das comunidades realizam a cooperação com os demais para que todos pudessem sobreviver.

\subsection{Importância do Ensino Cooperativista nas Escolas}

O ensino do cooperativismo nas escolas é a base para formação de um indivíduo que irá crescer e conhecer o sentido do cooperativismo, despertando uma consciência solidária. É de grande relevância que a educação cooperativista seja implementada nas escolas visto que essas crianças, serão os futuros colaboradores, gestores, dirigentes e construtores de Cooperativas.

Atualmente vivemos numa realidade que poucas pessoas conhecem e vivenciam o Cooperativismo. Estamos numa sociedade altamente individualista e competitiva. Segundo Cenzi (2009, p. 29) "o cooperativismo pode ser a salvação de muitos países, em quase todas as áreas".

Para Durkheim, a sociedade é uma determinante, e exige que o indivíduo se adapte totalmente aos seus objetivos. A educação é o principal instrumento dessa adaptação. É a educação que transforma a criança, desprovida de um senso social, numa peça ativa da sociedade.

A criança desde a fase inicial estará em processo de formação com espírito do Cooperativismo, praticando e desenvolvendo o seu instinto para esta área. As cooperativas serão lideradas por pessoas aptas que irão possuir entendimento e saber como os sistemas de cooperativas funcionam, o número de cooperados irá crescer e ainda mais estes cooperados farão parte de uma instituição que eles irão conhecer a fundo.

Com a implementação do ensino cooperativista existirão muitos profissionais formados e especializados nesta área, pois se todas as escolas aderirem a esta educação será necessária contratação de muitos profissionais desta área.

A educação cooperativista está atrelada com a cultura de cooperação esta que é uma ideia que se baseia num relacionamento de interdependência entre pessoas diferentes potencialidades com o objetivo de alcançar um bem comum. Com a educação cooperativista é possível formar pessoas solidárias e democráticas que se preocupam com o bem comum.

Nesse sentido, Jakobsen (1996) explica que educação cooperativista deve cumprir basicamente dois propósitos: a) socializar os membros no entendimento da lógica e dinâmica da organização de uma cooperativa e do seu papel como cooperados e b) equipá-los com ferramentas suficientes que os habilitem a pensar novas soluções segundo a lógica geral dos princípios e valores cooperativos, diante das crises e das necessidades de mudança e inovação. Neste último item englobam-se tanto técnicas de gestão e produção como conhecimentos específicos das mais variadas espécies, que melhorem o desempenho, tanto do produtor quanto da cooperativa.

O cooperativismo se sobrepõe ao individualismo, ele une as pessoas, fazendo com todos trabalhem juntos em busca de um objetivo, em que os associados trabalham juntos para o crescimento da cooperativa, pois será um ganho coletivo para todos, o cooperativismo fomenta a ideia de um capitalismo saudável e sustentável nas escolas, pois as crianças já crescem com este 
pensamento. Até no momento das dinâmicas aplicadas em sala de aula, pois no momento em que as tarefas são executadas em conjunto é possível alcançar um resultado melhor e em menos tempo.

\subsection{Educação como pressuposto para sociedade}

A sociedade e o bem-estar social são, hoje, elementos resultantes de ações humanas atribuídas à ideia do bem comum. A imagem transmitida para ilustrar o que venha a ser sociedade parte da premissa de junção entre as partes envolvidas que se trabalhadas em conjuntos cooperam para o bem maior. Cada ação humana no decorrer da história passou por diversas atribuições culturais e foram modificadas conforme o espaço e tempo vivido.

O viver em sociedade é proveniente do saber viver em sociedade que é um ensinamento transpassado de geração para geração através dos meios de ensino que moldam o conhecimento humano. A educação pode ser vista como pilar básico necessário a existência de todo ser humano. $\mathrm{O}$ ato de aprender é uma ação que pode ser comum a diversas espécies animais, porém o ato de ensinar e transmitir conhecimento é uma ação humana que o torna diferente.

Saviani (1991) mostra, porém, o caráter científico do ensino tradicional em suas origens é que:

[...] se estruturou através de um método pedagógico, que é o método expositivo, que todos conhecem, todos passaram por ele, e muitos estão passando ainda, cuja matriz teórica pode ser identificada nos cinco passos formais de Herbart. Esses passos, que são o passo da preparação, o da apresentação, da comparação e assimilação, da generalização e da aplicação, correspondem ao método científico indutivo, tal como fora formulado por Bacon, método que podemos esquematizar em três momentos fundamentais: a observação, a generalização e a confirmação. Trata-se, portanto, daquele mesmo método formulado no interior do movimento filosófico do empirismo, que foi a base do desenvolvimento da ciência moderna. (SAVIANI, 1991. p.55).

Ao se tratar de espécies inferiores onde a infância possui um período de tempo menor, a utilização da aprendizagem ocorre de forma demorada e insignificativa; quando se muda o cenário e é trazido o ser humano como centro do escopo a ser estudado, percebe-se a sua interação mutua com a aprendizagem a partir do seu processo de amadurecimento vivenciado desde a infância e continuado durante toda a sua trajetória de vida.

O processo educativo se dá desde o primeiro contato do indivíduo com o meio externo e então passa por mudanças e ajustes a sua faixa etária até alcançar o seu ápice de conhecimento que é atribuído a cada ser humano de forma particular. O indivíduo como ser pensante e racional é um ser dotado de experiências e conhecimentos que o permitem ter diversos comportamentos em meio a diferentes situações. As ações humanas são tomadas mediante uma análise do meio ambiente ao qual vive e baseadas nos ensinamentos obtidos. $\mathrm{O}$ homem só alcança a participação social como membro a partir do uso da educação que serve como portas de passagem para entrada ao convívio social.

A educação contribui ativamente para a existência da boa vivência em sociedade, atuando diretamente na sua manutenção e na inserção de novas ideias e formas de melhoramento que visam o bem comum. A cooperação entre as partes é vista como um processo evolutivo que trabalha em prol um dado grupo social afim de que as decisões tomadas beneficiem mutuamente todos os seus integrantes.

Infelizmente, cooperação e cooperativismo são conceitos pouco difundidos no âmbito social e educacional, fato este que questiona as bases da sociedade, visto que a ideia do bem comum coletivo, parte da cooperação entre todos os indivíduos que atuam de forma conjunta em prol do bem-estar social.

O cooperativismo pode ser visto como pressuposto básico que representa a ideia de sociedade voltada ao coletivo. A união de pessoas que trabalham na busca de soluções e resultados e no desenvolvimento de ações que contribuem para o bem da sociedade de forma que todos os envolvidos tenham acesso aos benefícios alcançados, pode ser entendido como significado de 
sociedade e como significado de cooperativismo. Ambos conceitos estão ligados e possuem significados complementares.

Entre os princípios cooperativos que direcionam as cooperativas podem-se encontrar o princípio da "Educação, formação e informação" e o princípio do "Interesse pela comunidade" que são alguns pilares regentes do bom funcionamento das diretrizes e ações que cada cooperativa precisa ter, além de estarem intimamente ligados com os interesses e benefícios sociais que esses princípios carregam.

As aplicações desses princípios cooperativos são atribuídas as atividades participativas que incluem a sociedade como um todo e reconhecem a suas importâncias e necessidades, além de contribuírem positivamente com o ambiente ao qual se está inserido, também promovendo mudanças sociais. Tais mudanças ocorrem a partir do uso e incentivo de pequenas ações e atitudes que são pensadas visando a continuidade do estado coletivo.

A educação, além de ser um direito natural do ser humano é uma forma de instigar a melhoria contínua de todos os processos que envolvem os aspectos sociais, relacionáveis, profissionais, afetivos, entre outros; a cooperação é uma forma de criar laços e promover a empatia sobre o desenvolvimento de bens e produtos, interesses de créditos, visões para a comunidade, agrupando indivíduos com interesses e pensamentos comuns de forma que os mesmo venham a atuar em conjunto visando os melhores resultados para aquele grupo social cooperativo.

O sociólogo Émile Durkheim (2001) afirma que a integração social é um fenômeno que existe independentemente das consciências individuais; e, ao menos sob o ponto de vista metodológico, o mesmo pode valer para a cooperação humana. Para o autor, os fenômenos sociais, a exemplo da cooperação, compreendem-se como "fatos sociais", estes que ocorrem de maneira externa nos indivíduos através de causas que escapam às suas ações e percepções subjetivas singulares. Ou seja, a cooperação seria, o resultado "natural" da extensa socialização, da institucionalização e da educação tanto formal, quanto informal sob as quais se desenvolve o indivíduo em sociedade.

\subsection{Exemplaridade social e a educação como fator determinante}

Em algum momento da vida a maioria das pessoas escutou falar sobre um famoso caso onde um dado rei encontrou duas crianças recém-nascidas à deriva. Ele queria saber quais línguas elas falavam e quais comportamentos teriam, então chamou duas amas de leite para cuidarem das crianças, mas não permitiu que houvesse qualquer tipo de interação entre aqueles bebês e qualquer pessoa em seu reino. Em um dado momento da história as crianças acabaram falecendo. Infelizmente, as crianças acabaram falecendo. Ao terminar de ouvir essa história é questionado a muitos, o motivo pelo falecimento das crianças já que as necessidades biológicas e fisiológicas lhes eram supridas, e pasmam-se todos ao perceber que as crianças morreram pela falta de contato humano e a falta de aprendizagem.

Esse caso expressa bem a fragilidade do ser em detrimento da falta do convívio social e a impossibilidade do aprendizado, tanto educacional quanto referente a valores e culturas, inerte a toda existência humana. A educação pode ser vista como um manual de instruções que norteará decisões e comportamentos mediante a situações de ação e reação.

A falta de conhecimento pode levar o homem a um estágio evolutivo anterior que é marcado pelo regimento e uso do instinto. A vivência em tal estágio não agrega nem coopera para o bem coletivo, ameaçando assim a existência do coletivo. É notória a necessidade que a sociedade de modo geral possui quando se trata de educação. O deficit não permite que o estado irracional tome partido das ações humanas, mas sim que o conhecimento transmitido seja mínimo comparado aos conhecimentos reais de direito.

O uso da educação contribui continuamente para a evolução humana, em aspectos individuais e coletivos. A capacidade de adaptação do homem mediante os eventos permite que ele se torne um ser capaz de modificar sua realidade e influenciar as realidades futuras. $O$ mundo atual não partilha da mesma visão de 50 anos atrás e não partilhará dessa mesma visão daqui a 50 anos. As constantes evoluções permitiram prever acontecimentos e a possibilidade de trabalhar em ações que reduzirão impactos negativos e maximizarão os impactos positivos. 
A atual realidade educacional presencia fatores políticos, econômicos e sociais que impactam diretamente sua gestão. Não se pode afirmar que as formas de ensino estão defasadas ou já não atendem as expectativas esperadas, visto que este ensino permitiu a atuação dos profissionais desta época; mas é clara a existência da necessidade evolutiva dos ensinamentos.

\subsection{A educação financeira}

A educação financeira surge como um desdobramento do processo de financeiro da economia que acaba por fazer com que os motivos e as práticas financeiras passem a permear a vida de indivíduos e famílias. Ela está alicerçada em duas premissas:

- A emergência da educação Financeira;

- A inserção de temas ligados ao mundo financeiro na esfera escolar.

Esta área tem como princípio a função fundamental de satisfazer as preferências de consumo das pessoas, inclusive todas as necessidades básicas da vida, além disso, metas financeiras das empresas e dos indivíduos frequentemente pressupõem interação com instituições e mercados financeiros, compreensão de impactos de impostos sobre o planejamento, entre outros assuntos ligados às Finanças.

A educação financeira remete a um intermédio em que é possível que os indivíduos compreendam a como fazer um bom uso do dinheiro, isto quer dizer que, poderão realizar tomadas de decisões conscientes e sustentáveis financeiramente.

Conforme a Organização para a Cooperação e Desenvolvimento Econômico (OCDE, 2005), a Educação Financeira consiste no processo pelo qual os indivíduos e as sociedades melhoram o seu entendimento acerca dos conceitos e produtos financeiros. Para tal, analisam três grupos de abordagens: informação, formação e orientação, para que os indivíduos possam desenvolver valores e competências que passam a ser primordiais para se tornarem mais conscientes das oportunidades e riscos envolvidos. Concomitantemente, poderão manifestar escolhas bem informadas, saberão onde procurar ajuda e ainda, praticar ações que irão melhorar o seu bem-estar. A OCDE (2005), ainda destaca que, deste modo, esses indivíduos contribuirão com responsabilidade e permanecerão comprometidos com o futuro.

A ausência do alcance a informação referente ao conhecimento financeiro, traz resultados indesejáveis, como falta do planejamento e orçamento financeiro, precipitações em tomadas de decisões e principalmente como citado anteriormente a falta de informações sobre o assunto, acabam dificultando a vida de grande parte da população.

Com grande crescimento e desencadeamento da economia o tema de educação financeira ganhou uma grande proporção e passou a ser um dos assuntos mais discutidos devido a sua importância para a sociedade.

Para Domingos (2014), a educação financeira nada mais é do que algo que auxilia a administração dos recursos financeiros, por meio de um processo de mudança de hábitos e costumes adquiridos há várias gerações. De acordo com o autor o ato de se educar financeiramente é uma técnica que ajuda no processo de gestão dos gastos e investimentos, que está sendo passado de geração para geração.

SILVA (2004), afirma que a realidade no Brasil é de que as pessoas não foram educadas para pensar sobre dinheiro na forma de administração, o que se vê é que a maioria gasta aleatoriamente sem refletir sobre o seu contexto financeiro e os impactos futuros. Poupar é importante, mas não é o suficiente. É preciso saber investir, escolher a modalidade mais interessante além da caderneta de poupança.

A educação financeira é uma maneira de obter conhecimentos, bem como informações sobre alguns comportamentos realizados pelas pessoas que irão refletir em futuras consequências, impactando principalmente na qualidade de vida, tanto individual, quanto coletivamente. Possuindo ainda um importante papel na sociedade sendo este o de promover o desenvolvimento econômico.

Ações descontroladas de oferta e demanda sendo realizada em conjunto ou individual na sociedade, refletem em graves consequências, gerando possíveis resultados de crises financeiras tanto familiares, quanto social. Diante disto surge a necessidade de aplicação no dia a dia dos consumidores o ato de refletir, se educar e praticar o clico financeiro através de planejamentos 
adequados, buscando adquirir produtos ou serviços que supram as suas reais necessidades, fazendo assim uma função importante no monitoramento do mercado.

A educação financeira para a população possui um grande significado, pois todos saem beneficiados, com resultados positivos. Através da mesma ocorre a possibilidade do equilíbrio das finanças pessoais, o preparo para futuros imprevistos que possam acontecer, possíveis riscos, qualidade do bom uso do sistema financeiro e até mesmos o caminho para realização dos sonhos.

Enfatizando o último ponto apresentado acima, a humanidade é movida pelos sonhos, estes que na maioria das vezes para realização exige-se a utilização de recursos em valor, então para los coloca em prática é necessária uma boa gestão financeira pessoal. Um grande problema enfrentando quando é mencionado o assunto é não saber como transformar os sonhos em realidade, para isto é preciso o desenvolvimento de uma visão clara sobre o tema abordado e ainda a transformá-los em projetos escritos, com características de tempo, ou seja, médio e longo prazo.

A disciplina orçamentária também está relacionada com o consumo consciente, ressaltando que o consumo feito de forma incorreta afeta os recursos naturais disponíveis no planeta terra, estes que são imprescindíveis para a sobrevivência da vida. Através do consumo inconsciente, geram-se consequências que afetam a qualidade de sobrevivência das presentes e futuras gerações. Daí levanta-se a questão que ao consumir deve-se ter percepção dos efeitos que podem acontecer no presente e futuro. O aproveitamento consciencioso na hora das compras de produtos e contratação dos serviços proporciona vantagens ambientais, sociais e econômicas, dessa maneira amplia-se o conceito da educação financeira, de modo que as escolhas de consumo passam a ser consideradas em tripé social, econômico e ambiental.

\subsection{A emergência da educação financeira}

A segurança financeira é o pilar para uma vida sem possíveis riscos financeiros, para emergências e imprevistos é essencial ter uma reserva financeira para garantia da tranquilidade da família, sendo uma qualidade de vida para o presente e para o futuro. Esta segurança é responsável por proporcionar qualidade na alimentação, na saúde, na moradia, nos estudos e ainda com transporte.

Uma garantia financeira acontece quando é possível conseguir quitar por um determinado período as despesas básicas de casa, como por exemplo, conta de água, luz, telefone, internet, entre outros, mesmo sem está recebendo dinheiro.

Para iniciar investimos em aplicações, por exemplo, é fundamental que se tenha uma reserva monetária para algum imprevisto que possa ocorrer. Quando na vida das pessoas há uma saúde financeira prejudicada, sequencialmente gera impactos na saúde do corpo, como estresse e até mesmo a ansiedade, a falta de proteção resulta em sentimentos de medo e incapacidade de lidar com situações, além de resultar em um problema gravíssimo os relacionamentos sociais. Muitas famílias são destruídas, perda de emprego, amizades, casamentos, sendo a principal causa a insegurança monetária.

O capital adquirido é imprescindível para garantir a estabilidade financeira familiar e proporcionar conforto e segurança a longo prazo. Como afirma Clason (2005) é preciso entender onde investir e como cuidar do que se sofreu tanto para conseguir. Uma das etapas que podem ser consideradas mais importantes do planejamento financeiro é determinar metas que nos deixem mais perto de alcançarmos nossos objetivos. Mas, essas metas precisam de data para se concretizarem. Muitas vezes, atingi-las em um curto espaço de tempo tornará mais fácil a realização dos sonhos.

\section{Procedimentos Metodológicos}

A presente pesquisa detém como base a abordagem qualitativa, sendo subjetiva e objetiva, podendo ser associada com a coleta e análise de texto (falado e escrito) e a observação direta do comportamento além da pesquisa-ação. Para confecção do artigo houve uma pesquisa descritiva, através de estudos bibliográficos para obtenção de conhecimento sobre o assunto abordado. 
A busca bibliográfica foi realizada com as seguintes palavras-chave: educação, cooperativismo e educação financeira. A partir da análise da produção preliminar, foram incorporados os estudos de Livros, Anais e Artigos.

A pesquisa bibliográfica pode ser considerada um procedimento formal com método de pensamento reflexivo que solicita um tratamento científico constituindo-se no caminho para se conhecer a realidade ou para que sejam descobertas verdades parciais. Mais que encontra a verdade, cujo significado é encontrar respostas para questões propostas, através de métodos científicos (LAKATOS; MARCONI, 2001). Tal pesquisa partirá de uma detida análise sobre "a educação cooperativa como gerador de mudanças sociais: um estudo sobre a 6. $\underline{a}$ semana da educação financeira na cidade de Itamaraju/BA".

A pesquisa ação segundo Prestes é desenvolvida principalmente nas ciências sociais, sendo aquela em que o pesquisador através de questionários, entrevistas, observações, etc, coleta seus dados, investigando os seus dados no seu meio.

A amostra bibliográfica final foi representada por estudos, selecionados por amostragem de conveniência. Durante o tratamento analítico dos dados, no primeiro momento, foi realizada uma pré-análise do material mediante uma pesquisa exploratória feita em livros relacionados ao cooperativismo e sua atuação cooperativa nos meios sociais, a educação e formas de aprendizagem, e também livros sobre técnicas de pesquisa, buscando identificar e conhecer o que foi publicado sobre o tema, para facilitar sua compreensão.

\subsection{Caracterização das escolas pesquisadas}

A pesquisa foi realizada em dois centros de ensino municipal na cidade de Itamaraju/BA, entre os dias 20 a 26 de maio de 2019, durante a execução das atividades da 6. a Semana Nacional da Educação Financeira, o primeiro deles foi a escola Municipal Benedita Malaquias do Nascimento, contendo 370 estudantes matriculados, de faixa etária de 4 a 14 anos, com uma estrutura de 8 salas de aula e 47 funcionários ao total incluindo professores e demais colaboradores.

O segundo foi o Colégio de nível médio Modelo Luís Eduardo Magalhães, tendo 930 estudantes matriculados, com idade de 13 a 24, com 31 de docentes, o ambiente escolar é composto por uma biblioteca, um laboratório de ciências, uma quadra de esportes, um laboratório de informática, contendo 12 salas de aula e 77 funcionários.

\subsection{Pesquisa-ação: Uma abordagem utilizada em duas escolas da cidade de Itamaraju/BA}

A pesquisa ação pode ser definida conforme aponta Thiollent (1985, p. 14) "um tipo de pesquisa com base empírica que é concebida e realizada em estreita associação como uma ação ou ainda, com a resolução de um problema coletivo, onde todos os pesquisadores e participantes estão envolvidos de modo cooperativo e participativo" é nessa perspectiva que será desenvolvido a presente pesquisa.

Seguindo o processo de definição do que é pesquisa-ação foi destacado segundo a visão de Gil $(2017,38)$, O termo "pesquisa-ação, foi cunhado em 1946 por Kurt Lewin, ao desenvolver trabalhos que tinham como propósitos a integração de minorias étnicas, à sociedade norte-americana”. Assim, definiu pesquisa-ação como uma pesquisa que não apenas contribui para a produção de livros, mas também conduz à ação social.

A metodologia da pesquisa-ação é utilizada através da coleta de dados, por meio de visitas na comunidade sendo registrados dados, como entrevistas, fotos, vídeos, entre outros. No desenvolvimento deste trabalho foram recolhidos depoimentos das crianças e dos jovens com a devida autorização e acompanhamento da direção e dos professores responsáveis pela sala de aula, os quais fizeram parte da pesquisa.

Conforme a realização da pesquisa nas escolas Bendita Malaquias e Colégio Modelo Luís Eduardo Magalhães, primeiramente houve o contato com a direção da escola para verificar e selecionar as turmas que mais necessitavam e estavam aptas a participarem ativamente da semana da 
educação financeira. Após este contato com a coordenação das escolas houve a escolha das turmas, onde foi possível identificar a real necessidade de cada de cada turma na participação nesta ação.

Após descoberta de quais seriam as turmas foram desenvolvidas as apresentações e montado as dinâmicas que seriam aplicadas as crianças e aos jovens.

Nestas visitas foram desenvolvidas atividades relacionadas a educação financeira com alunos de diferentes idades, permitindo assim que houvesse uma exploração mais "íntima" com os objetos de estudo do artigo em foco. A partir do conhecimento prévio, foram identificados núcleos em torno dos quais o presente estudo foi construído.

Sistematizando a análise seguiu os passos preconizados pelos autores, iniciando no primeiro contato com os alunos e informando-os sobre os conceitos financeiros e sua aplicabilidade correta, posteriormente seguindo com a leitura flutuante de artigos, captação de dados, leitura do material tangível e, por último, efetuando o tratamento e a interpretação dos resultados encontrados na pesquisa.

\section{Análise e discussão dos resultados: A Experiência com a 6a semana da educação financeira.}

O processo de pesquisa-ação será detalho em etapas, com o intuito de entender qual a lógica utilizada pelos discentes na educação financeira, o procedimento da pesquisa-ação aconteceu na 6. semana da educação financeira, onde foi posto em práxis algumas ideias sugeridas pelo BACEN para os estudantes.

Durante a 6a semana nacional da educação financeira proposta pelo Banco Central do Brasil, houve na cidade de Itamaraju localizada no Extremo sul da Bahia ações voltadas para esta semana, abaixo está descrito de forma detalhada as experiências realizadas em duas escolas neste período.

No dia 21 de maio de 2019, ocorreu na escola Municipal Benedita Malaquias do Nascimento, localizada na BR 101, km 807, bairro Alvorada, na cidade de Itamaraju/BA, uma roda de conversa com 48 crianças de idade entre o6 e o8 anos sobre educação financeira, no horário das 14:0oh às 17: oo. h. Nesta roda de conversa aconteceu uma dinâmica onde as crianças foram postas em círculo no qual foi entregue um rolo de barbante à criança que estava sentada na primeira cadeira da ponta do círculo, a mesma teria que pegar o barbante e responder a seguinte pergunta "de onde vem o dinheiro que entra na sua casa?", e assim sucessivamente até que virasse uma teia. A maioria das crianças respondeu que o dinheiro que entra na casa delas advinha dos bancos ou das fábricas, outras ainda afirmaram que o dinheiro se originava das roças, e teve aquelas que disseram que o dinheiro era provento da aposentaria dos pais ou ainda do benefício social bolsa família.

Logo após foi realizada outra dinâmica onde cada criança recebia uma bexiga vazia e dentro de quatro delas havia as seguintes perguntas "O que é o dinheiro? Você tem sonhos? O que você compra com o dinheiro? Você guarda dinheiro? ”, e em seguida as crianças enchiam as bexigas e as estouravam. Os quatro alunos que estavam com as perguntas dentro da bexiga que foram estouradas, dirigiram-se até a frente da classe e tendo o objetivo de responder aquelas questões, interagindo assim o com restante da turma.

Quando a primeira pergunta "O que é o dinheiro" foi lida, muitos deles responderam que o dinheiro seria simplesmente um pedaço de papel, alguns responderam que deveria ser algo valioso e outros ainda expressaram que dinheiro é o poder de compra. Referente a pergunta número dois todos responderam sim, uns queriam ser médicos, astronautas, bombeiros, possuir uma família, ou ter vários brinquedos.

Ao responderem a terceira pergunta as respostas foram doces, brinquedos, alimentos, ou ajudar os pais. Já na última pergunta as respostas foram mais simples, sendo utilizado apenas o não, o sim ou o famoso "guardar nos porquinhos".

Após esta dinâmica, lhes foi contada a historinha "Caio achou uma moedinha" da autora Gabriela Pelli. O livro conta sobre Caio que estava brincando com gato da vizinha e achou uma moedinha de $\mathrm{R} \$ 1$ 1,oo, mas não sabia direito o que fazer com ela. Com o passar dos dias, aquela moedinha virou duas...três...cinco...dez, e acabou se transformando em um grande sonho. Tudo porque, pouco a pouco, Caio aprendeu uma valiosa lição sobre querer poupar. 
Iniciado um momento de conversa com as crianças a partir da reflexão sobre a história, e perguntando-os qual era a lição que poderiam retirar da historinha, eles responderam que quando se poupa dinheiro é possível realizar sonhos, e que a partir daquele momento eles iriam começar a economizar suas moedinhas para realizar os seus sonhos.

Por fim a criançada respondeu uma atividade referente a historinha de Caio, onde tinham que recortar desenhos de dinheiro. Posterior a isto, elas foram a um local no evento onde havia sido montada uma pequena lojinha de brinquedinhos para cada criança comprar o que lhe agradasse com seu dinheiro de mentira. Cada uma tinha direito a comprar um brinquedo, seguindo uma de cada vez. Como eles já sabiam a importância do dinheiro, gasta-lo se tornou uma ação mais consciente. Ao final eles disseram que naquela tarde puderam compreender o real significado do dinheiro e a sua importância, além de aprender sobre como economizar e se sentiram felizes por participarem deste evento, adquirir conhecimento e poder praticar o que havia aprendido.

A essência do cooperativismo foi apresentada àquela turma. Com a prática e com o conhecimento correto as crianças em geral, com famílias de baixa renda tiveram a oportunidade de conhecer, talvez pela primeira vez, a educação financeira. Isso prova a importância da necessidade de atos cooperativos que a sociedade possui.

Já no dia 24 de maio de 2019, ocorreu duas palestras no Colégio Modelo Luís Eduardo Magalhães, localizado na rua Irmãos Andrada, bairro Jaqueira, N. 1635, na cidade de Itamaraju/BA, nos horários de 1oh:ooh e 16h:ooh. Com o tema "Educação financeira", sendo direcionada aos líderes e vice-líderes de sala com idade entre 16 a 20 anos, totalizando 52 alunos de turno matutino e vespertino.

No início foi apresentado alguns ditados populares que muitas pessoas dizem a respeito do dinheiro, como "tem que rico para ser feliz", "dinheiro não dá em árvore”, entre outras. Muitos dos participantes disseram que já ouviram tais ditados.

$\mathrm{Na}$ continuação foi direcionada as seguintes perguntas "O que é dinheiro? E o que ele significa para você? ", alguns responderam é algo que se pode trocar por outra coisa que tem valor, ainda disseram que o dinheiro é muito bom, pois tendo ele é possível comprar e ter várias coisas ao mesmo tempo, naquele momento expressaram também que se sentem felizes quando possuem o dinheiro, porém quando gastam sem necessidade se sentem tristes por não ter poupado.

Questionados se já haviam pensando ou planejado fazer uma viagem de final de ano com toda a classe expressou que nunca haviam pensado, mas a partir daquele dia eles iriam planejar uma viagem, pois iniciaram uma nova visão do conceito do dinheiro e como utilizá-lo de forma correta.

Ainda, perguntado se eles tinham sonhos, a maioria respondeu sim e citaram alguns ("entrar na faculdade", "ser especialista na área financeira", "comprar um celular, uma moto ou até mesmo um carro"). Alguns, ainda expôs que o sonho é ser músico ou médico. Para começar a realizar estes sonhos são necessários desenvolver um projeto. Foi aplicado uma dinâmica a turma, cada um recebeu uma "planilha dos sonhos" nela continha campos para descrever os sonhos de curto, médio e longo prazo e o valor para realizá-los. Eles levaram-na para casa e tomaram aquela planilha como projeto de vida.

Foi explicado a eles a diferença entre poupar e economizar, muitos já sabiam a diferença outros ainda se confundiam com os dois termos. Perguntados se poupavam dinheiro, alguns explanaram que sim, outros não, e justificaram que pela falta de trabalho não podiam guardar e neste ponto que foi ensinado aos estudantes que mesmo sendo pouco poderiam poupar sim e foi revelado a importância de poupar.

Naquele dia os estudantes da escola citada acima vivenciaram o sentido do cooperativismo através da educação financeira, sendo de total relevância a eles. Ações como estas são capazes de transformar a vida de jovens cheios de sonhos a serem praticados, além auxiliar no desenvolvimento do pensamento em relação às tomadas de decisões financeiras.

\section{Conclusões}

Através da experiência descrita foi possível observar que muitas crianças e a maioria dos jovens ainda não possui um conhecimento direto sobre o dinheiro, e não sabem como lo utiliza de 
forma correta para a realização de seus sonhos. Com tal situação é possível comprovar a importância da educação cooperativista para contribuir na formação e na mudança do pensamento das crianças e dos jovens no desenvolvimento da educação financeira.

As abordagens teóricas que embasam este estudo demonstram o quão é relevante o desenvolvimento do tema da educação financeira e na aplicação do ensino cooperativista, tanto para a sociedade como um todo, quanto para as crianças e jovens que receberão ensinamentos sobre cooperação desde a fase inicial de suas vidas, através do ambiente escolar o qual estão inseridos.

É na sala de aula que os estudantes começam o processo de formação de seus hábitos e, em razão do contato com a educação cooperativista e com o aprofundamento do tema da educação financeira, estes passarão a praticar tais conhecimentos em seus comportamentos diários. Deste modo, espera-se que eles possuam consciência sobre como planejar-se financeiramente de maneira adequada e sonhadora sobre seu futuro, agindo de forma cooperativa.

Diante do exposto, este estudo buscou descrever sobre a importância da aplicação do ensino como base para construção do modo de vida do indivíduo e sobre a influência da didática cooperativista na formação e na mudança de pensamento de crianças e jovens, a partir do ensino e da vivência de experiências efetuadas em escolas municipais na cidade de Itamaraju/BA.

Portanto, conclui-se, que o ensino cooperativista é um pilar importante para o desenvolvimento de crianças e adolescentes que serão o futuro da sociedade. Sua principal fundamentação encontra-se na implementação desses conceitos nos meios de ensinos escolares, pois a partir do convívio e da aplicação do aprendizado cooperativista, os juvenis fortalecerão suas atividades financeiras e sociais na comunidade o qual se está inserido, por meio de comportamentos financeiros realizados da forma adequada, além da compreensão sobre o trabalho em equipe, percebendo que quando a ação é realizada em conjunto se têm maiores chances de resultados satisfatórios e positivos; e ainda é de conhecimento que todos os cooperados possuem benefícios e vantagens. Por fim, ressalta-se o quanto é importante possuir uma vida financeira equilibrada, além de aprender que o ato de poupar hoje refletirá na capacidade de conquistar algo almejado no futuro.

\section{Agradecimentos}

Agradeço em nome da pessoa jurídica a Faculdade de Ciências Sociais Aplicadas ao qual faço parte do quadro de graduandos, aos docentes desta instituição que realizaram o papel de corretores deste trabalho o professor Emanuel Vieira Pinto e o professor Gustavo Melo de Souza, agradeço também a Cooperativa de Crédito do Médio Sul Baiano - Sicoob Costa do Descobrimento, o qual faço parte do quadro de colaboradores e parte da equipe do instituto Sicoob, agradecimento especial a coautora deste artigo por auxiliar no desenvolvimento deste estudo e pôr fim a OCB Organizações de Cooperativas do Brasil por realizar uma das funções de incentivar e motivar o desenvolvimento de pesquisas científicas.

\section{Referências}

ABRANTES, José. Associativismo e Cooperativismo: como a união de pequenos empreendedores pode gerar emprego e renda no Brasil. Rio de Janeiro: Interciência, 2004. p. 35-54.

CAMPOS, Dinah Martins de Souza. Psicologia da aprendizagem. Petrópolis: Editora Vozes, 2000

CENZI, Nerii Luiz. Cooperativismo: Desde as origens ao projeto de lei de reforma do sistema cooperativo brasileiro. Curitiba: editora afiliada, 2009. p 29.

CLASON, George S. O homem mais rico da Babilônia. 18 ed. Rio de Janeiro, RJ. Ediouro, 2005.

COUTO, Eduardo Andrade. Princípios cooperativistas na prática: análise de gestão social da COOPVALI/BA. Vila Velha: Opção Editora, 2014. 
DOMINGOS, Reinaldo. Educação financeira e finanças pessoais: qual a diferença? Disponível em: $\quad$ https://www.dsop.com.br/blog/educacao-financeira-e-financas-pessoais-qual-a-diferenca. Acesso em: 16 outubro de 2019.

DURKHEIM, Émile. As regras do método sociológico. São Paulo: Martin Claret, 2001.

GIL, Antonio Carlos: Como elaborar projetos de pesquisa. São Paulo: Atlas, 2017.

HAIRE, Mason. Psicologia aplicada a administração. São Paulo: Livraria Pioneira Editora, 1974.

JAKOBSEN, G. When business leads to cooperative development: a study ofeducational processes in a cooperative firm. In: Review of International Cooperation. v. 89/2, p. 25-33, 1996.

LAKATOS, E. M.; MARCONI, M. A. Metodologia do trabalho científico. São Paulo: Atlas, 2001.

OCDE. Recommendationon Principles and Good Practices for Financial Education and Awareness. Paris, 2005. Disponível em: <http://www.oecd.org/ daf/fin/financialeducation/3510856o.pdf>. Acesso em: 03 junho 2019.

PELLI, Gabriela. Caio achou uma moedinha. Brasília: Instituto SICOOB.

PRESTES, Maria Luci de Mesquita. A pesquisa e a construção do conhecimento científico: do planejamento aos textos, da escola à acadêmica. São Paulo: Editora Rêspel LTDA, 2005.

PRESTES, Maria Luci de Mesquita. A pesquisa e a construção do conhecimento científico: do planejamento aos textos, da escola à academia. São Paulo: Respel editora, 2005. p. 27.

PINHO, Diva Benevides. O Cooperativismo no Brasil: da verdade pioneira à vertente solidária. São Paulo: Saraiva, 2004.

RIOS, Gilvando Sá Leitão. O que é Cooperativismo. São Paulo: Brasiliense, 2007

SAVIANI, D. Escola e democracia. 24. ed. São Paulo: Cortez, 1991. p. 55.

SEBRAE, Revista Cooperativa de Crédito. 2009

SILVA, Eduardo D. Gestão em Finanças Pessoais: uma metodologia para se adquirir educação e saúde financeira. Rio de Janeiro: Quatymark, 2004. 